\title{
Análise de Conceito dos Paliativos Oncológicos Numa Perspectiva da Humanização do Cuidado em Saúde
}

\author{
Amorim, Rosendo Freitas de; Santos, Loyse Gurgel dos; Landim, Fátima Luna Pinheiro; Frota, \\ Mirna Albuquerque; Saintrain, Maria Vieira de Lima; As, Zélia Maria de Sousa Araújo; Catrib, \\ Ana Maria Fontenelle \\ Universidade de Fortaleza — rosendo@unifor.br
}

Introdução: Cuidado paliativo é uma abordagem multidisciplinar que alivia o sofrimento e oferece melhora na qualidade de vida do paciente e seus familiares, diante de uma doença avançada e terminal, por meio de habilidades e conhecimentos específicos. o cuidado humanizado desses pacientes intenciona alívio e controle da dor e uma assistência integral. a humanização do cuidado aborda aspectos que exigem uma atenção dos profissionais de saúde desde os cuidados específicos da profissão, no caso, a fisioterapia, até a percepção do quadro na sua totalidade, em que estão presentes a dimensão da existência e a possibilidade da morte. Objetivos: Reconceituar a categoria cuidados paliativos numa perspectiva da humanização do cuidado em saúde. Metodologia: o estudo constitui-se numa revisão de literatura, configurando-se numa pesquisa de natureza qualitativa. a investigação permitiu um processo de reconceituação da categoria cuidados paliativos à luz da humanização do cuidado em saúde. Nesse sentido, a pesquisa abordou o significados das relações e ações humanas nos contextos de atuação dos profissionais da saúde, em especial o fisioterapeuta, algo não mensurável por equações ou fórmulas estatísticas. Investigou-se, portanto, as concepções de cuidados paliativos construídas pelos nos textos estudados, considerando teorias e concepções, bem como os valores humanos com destaque para o enfoque dos elementos epistemológicos e socioculturais. Realizou-se nos meses de março, abril e maio de 2013, levantamento nas bases de dados Lilacs, PubMed e Scielo, usando os descritores "cuidados paliativos"e " humanização do cuidado". Trata-se de um estudo analítico das concepções de cuidados paliativos de pacientes oncológicos numa perspectiva da humanização do cuidado. Resultados: Percebeu-se durante a análise de conceito cuidados paliativos oncológicos o esforço dos especialistas da área em construir uma elaboração rigorosa dessa categoria. um dos pontos referenciados reside no fato desse profissional ser capacitado em toda sua vida acadêmica para tratar a dor dos pacientes, de forma a eliminá-la. Porém, nesses casos de pacientes idosos com quadro de câncer avançados e sem possibilidade de cura, sofrendo de intensas dores e principalmente, dores que o fisioterapeuta não é capaz de resolver, os mesmos relatam que não foram treinados para vivenciar essas situações, daí a sensação de impotência. Conclusões: Constatou-se que apesar da complexidade epistemológica do conceito de cuidados paliativos, houve um considerável avanço no processo de consolidação teórica da categoria. Entretanto, a hipótese inicial desse estudo confirmou-se: a incipiente relação entre a categoria e a de humanização do cuidado. a originalidade do presente estudo residiu em reelaborar o conceito de cuidados paliativos enriquecido com as contribuições da humanização em saúde, condição sine qua non para que ele tenha um significado pertinente.

Amorim, Rosendo Freitas de; Santos, Loyse Gurgel dos; Landim, Fátima Luna Pinheiro; Frota, Mirna Albuquerque; Saintrain, Maria Vieira de Lima; As, Zélia Maria de Sousa Araújo; Catrib, Ana Maria Fontenelle. Análise de Conceito dos Paliativos Oncológicos Numa Perspectiva da Humanização do Cuidado em Saúde.. In: Anais do Congresso Internacional de Humanidades \& Humanização em Saúde [= Blucher Medical Proceedings, num.2, vol.1]. São Paulo: Editora Blucher, 2014. ISSN 2357-7282

DOI 10.5151/medpro-cihhs-10642 